\title{
Towards Comparative Measures of Circulation: Insights from Indigenous Australia
}

\author{
John Taylor ${ }^{1, *}$ and Martin Bell ${ }^{2}$ \\ ${ }^{1}$ The Australian National University, Centre for Aboriginal Economic Policy Research, Canberra, Australia \\ ${ }^{2}$ School of Geography, Planning and Environmental Management, The University of Queensland, Brisbane, Australia
}

\section{ABSTRACT}

Circulation and other forms of temporary movement are of rising importance in the context of overall population mobility. Despite this, analysis is constrained by a lack of appropriate data and techniques for developing summary measures. Ethnographic methods have afforded useful insights into the complex space-time circuits and lifetime sequences involved, but without quantitative indicators these forms of mobility are effectively invisible to researchers and policy makers. Building on prior work in developing countries we advance methodologies for summarising the temporal dimension of circular mobility. Using illustrative data drawn from a variety of field studies among indigenous peoples in Australia we show how lifelines tracing individual mobility profiles can be used to generate systematic measures of frequency and duration. When plotted graphically these reveal distinctive periodicities that correspond to particular forms of mobility behaviour. Because these metrics are scalable and readily amenable to collection in general surveys they offer a unique bridge between the richness of detail that flows from biographic approaches and the aggregate metrics needed for statistical comparison. Copyright @ 2011 John Wiley \& Sons, Ltd.

Accepted 19 September 2011

${ }^{*}$ Correspondence to: John Taylor, The Australian National University, Centre for Aboriginal Economic Policy Research, Canberra, Australia. E-mail: j.taylor@anu.edu.au

Note: Correction added on 01 December 2011 after first publication online on 17 November 2011. Due to an error during production, the name of the second author of this article, Martin Bell, was included as part of an affiliation instead of as an author. This has now been corrected to show authorship by John Taylor and Martin Bell.
Keywords: population mobility, circulation, indigenous peoples, periodicity

\section{INTRODUCTION}

I $\mathrm{t}$ is now widely recognised that ethnographic and biographical approaches present an essential perspective on population mobility (Halfacree and Boyle, 1993; Lawson, 2000; McHugh, 2000). In recent years, this has been underlined by the emergence of the spatial turn in sociological literature (Creswell, 2006; Sheller and Urry, 2006). From somewhat differing standpoints, it is argued that these provide a richness of detail that enables the proper interpretation of population movement as culturally situated in social fields and individual and group life courses. Although such approaches undoubtedly add texture and meaning to analyses of human mobility, less attention has been paid to the continuing need for measurement techniques that capture the complexities of movement over space and time in such a way as to also enable comparison between regions, temporal settings, and types of movers. Efforts to achieve such measurement are fairly long-standing, though sporadic. A useful summary is provided by Taylor (1986). From this, it can be seen that data on the frequency of moves and duration away from a home base have generally been used as the means to calibrate circuits of movement. Although this has provided useful metrics as to the extent and character of circular moves for individuals, a major drawback is the limited capacity for comparison between individuals and groups. More recently, Bell (2004) has shown how duration and frequency can be combined with information on the sequences of movements to generate a new comparative metric - that of periodicity. In practice, though, exploration of 
the nature of periodicity and its meaning has been restricted by an absence of suitable, reliable data on the timing of population movements and the limited development of techniques to derive summary indices. There are compelling reasons for further methodological development in this area, and ethnographic data gathered to illuminate aspects of indigenous Australian sociality provide fertile material for demonstrating how this can be achieved.

The analysis of population movement among indigenous peoples in Australia, and no doubt elsewhere, faces a dilemma. On the one hand, there is overwhelming evidence from a substantial body of ethnographic research to indicate that indigenous population movement is chronic in occurrence - some call it 'hypermobility' (Morphy, 2007) - and is predominantly non-permanent, short-term, and circular in nature (Taylor and Bell, 2004; Prout, 2009a). On the other hand, the primary source of statistical information on indigenous mobility remains the 5-yearly census, which only produces data on changes in 'usual residence' over 1 and 5-year intervals. Periodic surveys provide supplementary data, such as reasons for moving and number of moves over a defined interval, but they are prejudiced by sampling variability and the fact that mobility is rarely the principal focus. Neither Censuses nor Surveys yield data on population movement that come anywhere close to matching the rich texture of hypermobility that emerges from ethnographic accounts of indigenous daily life.

Against this background, there is growing recognition of a need for practical ways to bridge the perceived binary division between quantitative and critical approaches to human geography (Schwanen and Kwan, 2009). In the context of population mobility, these approaches are embodied in sharply contrasting scholarly traditions: the former focused on sets of rigorously defined, internationally comparable statistical indicators, driven by aggregates, which measure the intensity and redistribution arising from residential change (Stillwell and Congdon, 1991; Bell et al., 2002); the latter grounded in the specific historical context of indigenous experience that stresses the role of local contingency in shaping individual patterns of human movement (Chapman and Prothero, 1983; Peterson, 2004).

It is in the search for some middle ground to bridge these two approaches, blending the unique quality of individual biography with metrics that capture key dimensions of circular mobility, that we seek to contribute. Using longitudinal mobility data drawn from various field studies based on participatory research methods applied in remote parts of Australia, we aim to demonstrate that at least one dimension of circulatory movements their periodicity - can be measured and reported systematically in a manner that enables comparison between different types of movement. In short, we aim to show that the richness and detail that flows from biographic approaches can be linked to a metric that enables direct and meaningful statistical comparison between movers, paralleling similar recent developments in regard to permanent migration (Bell et al., 2002).

\section{WHY MEASURE CIRCULATION?}

As recently argued in the case of permanent migration (Bell et al., 2002), there are a number of reasons to call for a more systematic approach to measuring non-permanent forms of population movement. Development of a set of standard statistical indicators should encourage and equip researchers to adopt a rigorous approach to measuring the phenomenon and provide the basis for comparative analysis. Research describing mobility in differing spatial or social settings takes on greater meaning when placed in a comparative framework. As commonalities and differences between various forms of mobility become more readily apparent, this aids classification and theorisation. At a fundamental level, it also seems inherently sensible to establish a common framework against which to interpret the myriad forms of mobility that share many key features in common. Indeed, one clear benefit of a standard metric would be to promote greater coherence, if not integration, among a remarkably fragmented literature (Larsen et al., 2006).

Strong practical arguments for statistical indicators of circulation can also be found. Most prominent among these is the need to understand the spatial and temporal dynamics of mobility in a form that can help guide the efficient and timely provision of services, such as health and education, to mobile populations. Although conventional methods of service delivery are founded on fixed locations and mainstream calendars, such notions are poorly suited to meeting the needs of populations, such as indigenous Australians, whose space-time references can be grounded in quite different realities (Prout, $2009 b$ ). One corollary of this chronic mobility is that the population of individual localities 
fluctuates continuously in periodic cycles over the course of a year (Charles-Edwards et al., 2008). This, in turn, brings into serious question the validity of a single, estimated 'de jure' population of hypothetical usual residents as a suitable measure for service planning. The notion of a 'service population', which better captures the true population in need of particular services (Australian Bureau of Statistics, 1996, 1999) is conceptually appealing and considerable progress has been made in estimating 'temporary populations' (Smith, 1989, 1994, 2007; Longino and Marshall, 1990; Bell and Ward, 1998; Bell and Brown, 2006; Silm and Ahas, 2010). Nevertheless, measures of the size and characteristics of the service population in any given locality would be significantly enhanced by better understanding of the underlying population movements. For innovative forms of service delivery, such as travelling classrooms that accompany circular migrants (Danaher et al., 2006), such knowledge is indispensable.

\section{TOWARDS A METHODOLOGY}

In practice, the task of assembling a comprehensive set of measures of temporary mobility is by no means straightforward. Even in the field of permanent migration, differences in the way migration is captured in statistical collections, together with the traditional problems arising from the division of space and the measurement of distance, have severely handicapped comparative analysis, and proposals for robust general measures have only recently emerged (Rees et al., 2000; Bell et al., 2002). In the case of temporary mobility, these problems are compounded by the multidimensional nature of the phenomenon. In shedding light on this issue, Bell and Ward (2000) identified a series of differences between permanent and temporary migration, most prominent among which were the latter's variable duration, repetitive nature, and seasonal variation. More recently, Bell (2004) has identified nine discrete dimensions of population movement each of which, it is argued, describe a particular facet of the phenomenon. These dimensions are movement intensity, duration of stay, frequency of movement, timing, seasonality, movement distance, spatial circuits, spatial connectivity, and spatial impact. Here we elaborate on the temporal dimensions in this list as the key to developing a single metric that captures the overall periodicity of circulation.
Previous efforts to develop summary measures of circulation have generally been confined to non-Western populations. They originated in Africa and the Pacific among social scientists anxious to quantify the process of gathering urbanisation (Gould and Prothero, 1975), and the most prominent are shown in the following text box.

Box 1. Summary indices of circulation

1. Index of labour stabilisation (Mitchell, 1956): this is calculated as $\frac{\text { years in town since age } 15}{\text { years lived since age } 15} \times 100$.

2. Stabilisation curve (Alverson, 1967): total time spent in town graphed as a function of cumulative age.

3. Circulation index (Bedford, 1973: 212): this modifies the accessibility index within a network to produce a circulation index $C(i, S)$ :

$$
C(i, S) \frac{\sum_{j=1}^{n} L(i, j)}{v-I} .
$$

'Where $v$ is the total number of nodes in the network. By dividing the summed distance of all nodes ( $j$ ) from the home village (i) by the number of nodes minus the home village, the actual size of the network (in terms of the number of nodes) becomes irrelevant, and the degree to which circulation in the network has occurred is the significant feature' (Bedford, 1973: 212).

4. Index of circular migration (Young, 1979: 46):

Number of return moves to the village $\times 2$

$$
\text { Total number of moves }
$$

Thus, values range from 100 (maximum intensity of circulation where every outward move is followed by a return to the village) to zero where no return move has thus far occurred.

5. Velocity of circulation (Standing, 1982: 36):

Velocity of circulation $=\left(\frac{\bar{t} \cdot \bar{n}}{T} \times \frac{M}{P}\right) \times 100$.

,Where $\bar{t}$ is the average duration of time away for those who circulated, $\bar{n}$ is the average number of absences among such migrants in the period, $T$, which itself could be a year expressed in the same units as $t$ (days or weeks). $M$ is the number of those involved in circular migration (however defined), and $P$ is the population "at risk"' (Standing, 1982: 36). 
Thus, in southern Africa, Mitchell (1956) created an index of labour stabilisation defined as the changeover from circular population movement to permanent residence in town. Although this provided an indirect measure of circulation it suffered from the fact that equivalent stabilisation scores could be obtained for individuals with vastly differing lengths of stay in town and it provided no indication of the patterning of time spent in rural and urban areas. In an attempt to overcome these shortcomings, Alverson (1967) used longitudinal data to plot the total time spent in town as a function of the cumulative age of migrants for successive 3-year intervals of an individual's migrant career thereby producing a stabilisation curve. In this arrangement, the slope of any curve, or curve segment, is isomorphic with the rate at which time spent in town accumulates relative to total time elapsing. Although this reflected the temporal features of mobility with greater precision, it also involved a level of generalisation that compromised much of the valuable detail embodied in the data, notably that concerning the frequency and spacing of movements.

Subsequent indices of circulation were developed in the Pacific region using graph-theoretic techniques to measure the balance of circular and stepwise movements (Bedford, 1973), with the intensity of circulation determined as a ratio of return circuits to all moves made from a given place (Young, 1979). One refinement to these techniques was the development of the velocity of circulation that accounted for the average duration of time away for those who have circulated (Standing, 1982). In each of these cases, however, it remained simply the degree of circularity in the overall context of total mobility that was being measured, whereas we argue here that the real challenge in summarising longitudinal mobility data is to develop a summary index that preserves the details of frequency, duration, and (ideally) timing.
An attempt to address the first two of these requirements was made by Taylor (1986) building on the idea of lifelines originally developed by Hägerstrand (1963). This posited two simple indices of circulation that can be viewed in combination. The first captures the number of cycles of movement that occur within a defined time interval, $t$, where a cycle is measured as one completed circuit from the time of departure from home on circuit one, to the point of imminent departure again on circuit 2 (described by the sequence A-B-C-D in Fig. 1). This is referred to as the frequency of movement, $f$. The second index, $p$, calculates quite simply the proportion of the total time, $t$, spent away from home. Frequency is effectively measured on an open-ended scale, ultimately constrained only by the value selected for $t$, whereas $p$ must lie in the range $0 \geq p \geq 1$ where, as $p \rightarrow 1$, time away from home is maximised. Taylor (1986) used these indices to track the evolution of circular mobility among mine workers in Botswana over a number of years by presenting the results as overlapping histograms on a graph with two separate $y$-axes.

Although this provides some scope for comparison of mobility outcomes, Bell (2004) shows that this capacity can be substantially enhanced by representing the frequency and duration of different movement schedules on an $x-y$ scatter graph. In representational form, the simple innovation here is the creation of a space within which varying types of circulation can be located as in Figure 2.

Thus, the lower left quadrant captures temporal behaviour that involves relatively long cycles of which only a small proportion is spent away from the home base. Moving to the right along the $x$-axis reduces the length of the cycle, hence raising the frequency of movement but still resulting in only short absences. Located higher on the graph, in the upper quadrants, issues arise as to the proper meaning of 'usual' place of

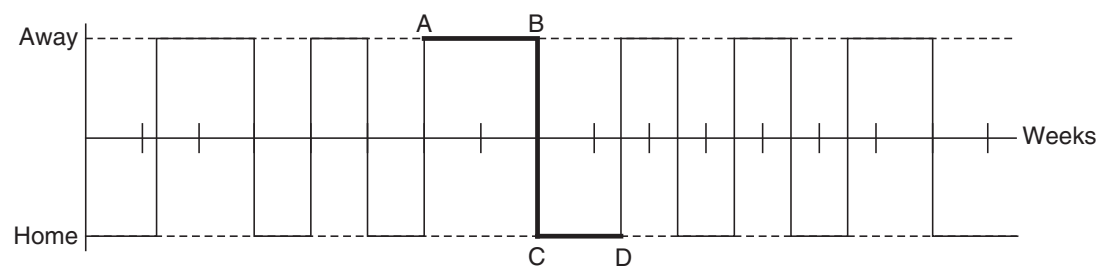

Figure 1. Lifeline of hypothetical circulator. Source: modified after Taylor (1986). 


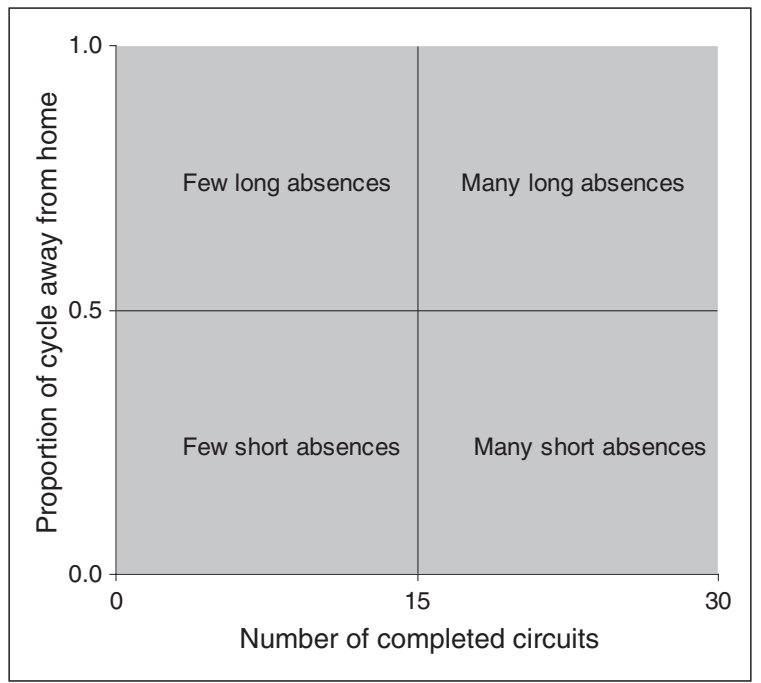

Figure 2. Periodicity of circulation.

residence because periods of absence increase and may exceed the periods spent resident at the 'home base'. This issue arises most clearly in the upper left quadrant where the low frequency of movement limits the number of alternate residential sites, whereas in the upper right quadrant there could be multiple locational options away from home thereby rendering the latter more clearly defined. To demonstrate how these spaces might be populated, we use a selection of ethnographic data on the movements of indigenous Australians over a 1 year span.

\section{INDIGENOUS CIRCULATION: ILLUSTRATIVE TYPES}

A recurring theme in ethnographic research among remote indigenous peoples in Australia is the recognition of circuits of movement between places that combine to form functional regions (Taylor and Bell, 2004; Prout, 2009a). These movements are influenced by a mix of considerations that reflect the persistence of longstanding customary practices alongside pressures for change. Thus, on the one hand, mobility is shaped by continuity in attachment to traditional lands and the maintenance of kinship ties; on the other hand, there are influences for change brought about by engagement with modernising institutions such as education, training, and formal employment, as well as by access to often distant essential services, notably health services
(Coulehan, 1995). It is often the balancing of these forces for continuity and change that lead many indigenous people to engage in what one analyst has referred to as 'multilocale relationships' engendering high levels of circular mobility (Uzzell, 1976). Spatially, circuits of movement can be highly localised, but as indigenous people are drawn further into mainstream institutions, and as access to transportation increases, the spatial extent of circuits widens.

Given the spatial scale and temporal cycles of these movements, difficulties arise in distinguishing circulation from residential change. For example, many indigenous people are without a fixed residential base and reside instead in an 'area' within which they may be more or less permanently mobile. Indeed, if we follow Roseman (1971) and gauge the strength of an individual's social and economic ties because of relocation, much of what we see by way of indigenous peoples' mobility in contemporary Australia involves only 'partial displacement', despite sometimes lengthy and distant travel. Notwithstanding these interpretive difficulties, because circulation has long been recognised as an integral dimension of indigenous sociality it is not surprising to find that attempts have been made to quantify associated spatial and temporal patterns, albeit in an ad hoc way. Thus, although empirical data on time sequences of circulation are generally scant, in the case of indigenous Australians, we have information available from a long ethnographic tradition of inquiry mostly among anthropologists.

For the most part, data suitable to the task in hand have emerged from studies among populations in remote parts of the continent living within an indigenous domain - that is, in areas where Indigenous peoples and their institutions predominate. In regard to such populations, Taylor and Bell (2004: 17-28) have identified four main factors that serve to generate temporary absences from a home base: customary land use practices, social networks, access to services, and marginal socioeconomic status. Although it is difficult to argue that these are discrete explanatory categories, we nonetheless have sought to deploy data that are illustrative of sequential population movements associated with each of these. All these data are confidentialised public domain information and were derived from participatory research involving community representative organisations. 
In the case of land use, across much of remote Australia, and especially on indigenous lands in the tropical north of the continent, indigenous people still engage in hunting and gathering practices that are heavily influenced by seasonal cycles and involve temporary absences from a home base. The most detailed study of population movements associated with such activities remains that conducted by Altman (1987) among eastern Gunwinggu people of north central Arnhem Land, and data from this source are provided here in respect of one female adult from the small settlement of Momega. For an example of service access mobility, we draw on field data from a study conducted by Memmott et al. (2006) and sponsored by the Australian Housing and Urban Research Institute to illustrate the experience of a Dajarra woman in western Queensland who travels occasionally into the mining town of Mount Isa for shopping and to access medical services. These absences can become prolonged at times because of difficulties in finding return transport home combined with the lure of spending time with relatives in town.

For movement associated with social networks, we report the activities of a Dajarra man from the same study. This reveals the comings and goings of an individual engaged formally in part-time community work but who also places high value on the maintenance of linkages with kin and who travels a relatively wide area of western Queensland and into the Northern Territory for work and to visit and associate with extended family members. As a further example of an individual marginally attached to the workforce, we report the case of a community administrator in central Cape York Peninsula who is employed part-time but uses official access to vehicles and other resources to combine work with social obligations to kin located in small clan-based settlements across the region (Smith, 2000: 80-173).

By way of contrast to these four archetypes, we also present data concerning an indigenous man working full-time for a mining company (Argyle Diamonds) in the east Kimberley region of Western Australia. In recent years, mining companies have increasingly sought to engage local indigenous labour in mainstream work under the terms of mining agreements with local communities. To encourage this, one strategy adopted by the Argyle Diamond Mine is a shift roster of 2 weeks on/2 weeks off by bus-in/ bus-out from the regional town of Kununurra. This produces a highly regulated mobility pattern that combines the needs of mine work practices with a desire on the part of indigenous workers to remain in close contact with family.

These examples are reduced to their cyclic metrics in Table 1 and then located within the periodicity space in Figure 3. What emerges is a mix of mobility patterns scattered across the two axes. Of note is a tendency for mobility to lie in the lower two quadrants indicating strong commitment to a home base even if the frequency of movement may be relatively high. Thus, the Dajarra man in western Queensland, and the community worker in Cape York, both with time at their disposal and access to vehicles, engage in frequent short-term absences at weekends or for days at a time connecting with kin around their region and often combining this with workrelated movement. In contrast, the Dajarra woman is relatively immobile and drawn into Mount Isa only on occasion to access essential services. Even the mine workers who are fully committed to mainstream employment away from home maintain a balance of residence with the home base despite frequent absences.

Table 1. Typical cyclic components of circular mobility.

\begin{tabular}{|c|c|c|c|c|c|c|}
\hline $\begin{array}{l}\text { Type of } \\
\text { circulation }\end{array}$ & $\begin{array}{l}\text { Number of } \\
\text { cycles per } \\
\text { year }(f)\end{array}$ & $\begin{array}{l}\text { Length of } \\
\text { cycle }\end{array}$ & $\begin{array}{l}\text { Time } \\
\text { home }\end{array}$ & $\begin{array}{l}\text { Time } \\
\text { away }\end{array}$ & $\begin{array}{c}\text { Duration of } \\
\text { cyclic pattern }\end{array}$ & $\begin{array}{l}\text { Proportion of cycle away } \\
\text { from home }(p)\end{array}$ \\
\hline Seasonal land use & 4 & 3 months & 1 month & 2 months & Full year & 0.66 \\
\hline Social networks & 26 & 1 week & 5 days & 2 days & Full year & 0.28 \\
\hline Service access & 2 & 6 months & 4 months & 2 months & Full year & 0.33 \\
\hline $\begin{array}{l}\text { Community } \\
\text { employment }\end{array}$ & 48 & 7 days & 3 days & 4 days & Full year & 0.57 \\
\hline Bus-in/bus-out roster & 16 & 4 weeks & 2 weeks & 2 weeks & Full year & 0.50 \\
\hline
\end{tabular}




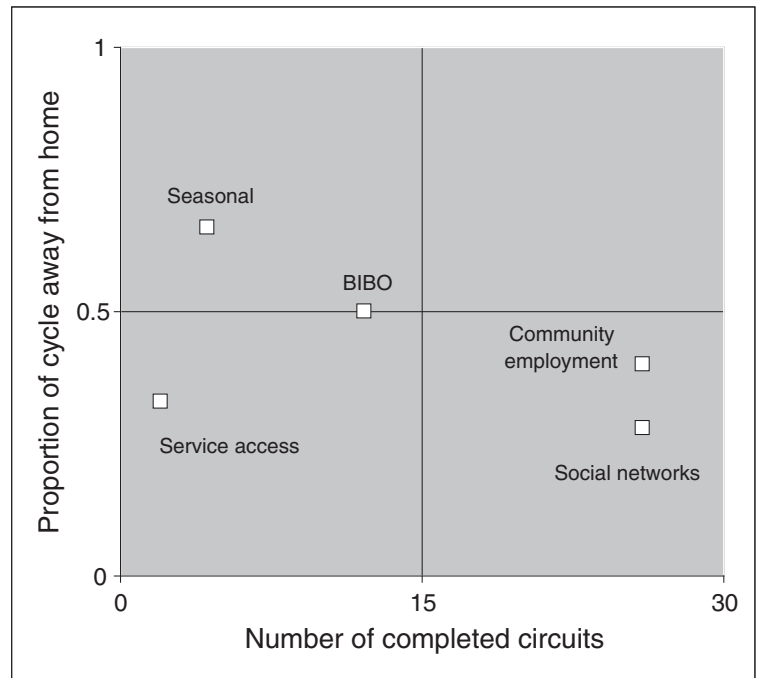

Figure 3. Frequency and duration away for selected types of indigenous circular mobility. BIBO, bus-in/bus-out.

Of particular interest is the woman in Arnhem Land who shifts residence according to the seasons with the ultimate effect of spending more cumulative time 'away' than at 'home'. Although this may seem to confuse the notion of usual place of residence, Momega remains the place of longest single duration with moves to other places seen as temporary relocations to secure shelter and town-based services in the wet season and access to bush resources in the dry. Although obviously confined by selection, it is interesting to note the absence of any examples of indigenous mobility from the top right quadrant. According to Bell (2004), in the wider society, this space is occupied by weekly commuters, salesmen, transport workers, and particular rostertype workers such as mine managers - in other words, individuals engaged in specialised activities, often trades or managerial workers, and precisely the type of occupations from which indigenous Australians are conspicuous by their absence (Hunter, 2004).

\section{TIMING AND SEQUENCING}

What the above measures cannot capture is the precise timing and sequencing of mobility circuits. Although many forms of circular mobility are associated with particular activities that dictate the sequence of days spent at home and away, in other cases the timing and sequencing are far more volatile. Thus, in the case of customary land use, seasonality (here associated with wet and dry periods) produces a broadly predictable framework for mobility, whereas many workplace arrangements (such as in the mining industry) impose an even more tightly regulated regime. In other instances, however, and particularly where movement for social reasons is involved, the timing and duration of temporary mobility can vary considerably with both of these often highly contingent and determined by chance encounters and events (Young and Doohan, 1989). The spatial extent of such movement, however, is invariably dictated by the distribution of kin and affiliation to particular territory. In recognising this variability, Prout (2009a) distinguished three discrete forms of transient mobility among indigenous people, differentiated primarily by the relationship with a home base. These comprised perpetual movement of the homeless, who travel more or less continually between households occupied by kin; circulation, which involves repeated returns to a 'home base' after frequent journeys away; and multilocale living, involving more regular seasonal movements between multiple residences. As archetypes, these might well be characterised by distinctive periodicities of a form that could be captured in Figure 3, but the multiple drivers of indigenous mobility inevitably superimpose a more sporadic time signature on any underlying regularities.

In practice, these sequences may be best represented graphically rather than by summary statistics, as illustrated in Figure 4 and as first attempted by Chapman (1975). When accompanied by qualitative accounts of significant related events they provide a quite powerful means of synchronising mobility behaviour with critical moments. Thus, in Figure 4, we see stable and relatively prolonged residence at Momega settlement during the late dry and early wet seasons replaced by a shift in location to the nearby township of Maningrida as the monsoonal rains set in and adequate shelter and access to services become paramount. By the end of the wet, people are anxious to return to the bush, and as the dry season sets in dispersion occurs across surrounding floodplains to harvest wild resources. At the end of this period, a return to home base is accompanied by much movement associated with ceremonial activity until the rains resume and the cycle restarts. 


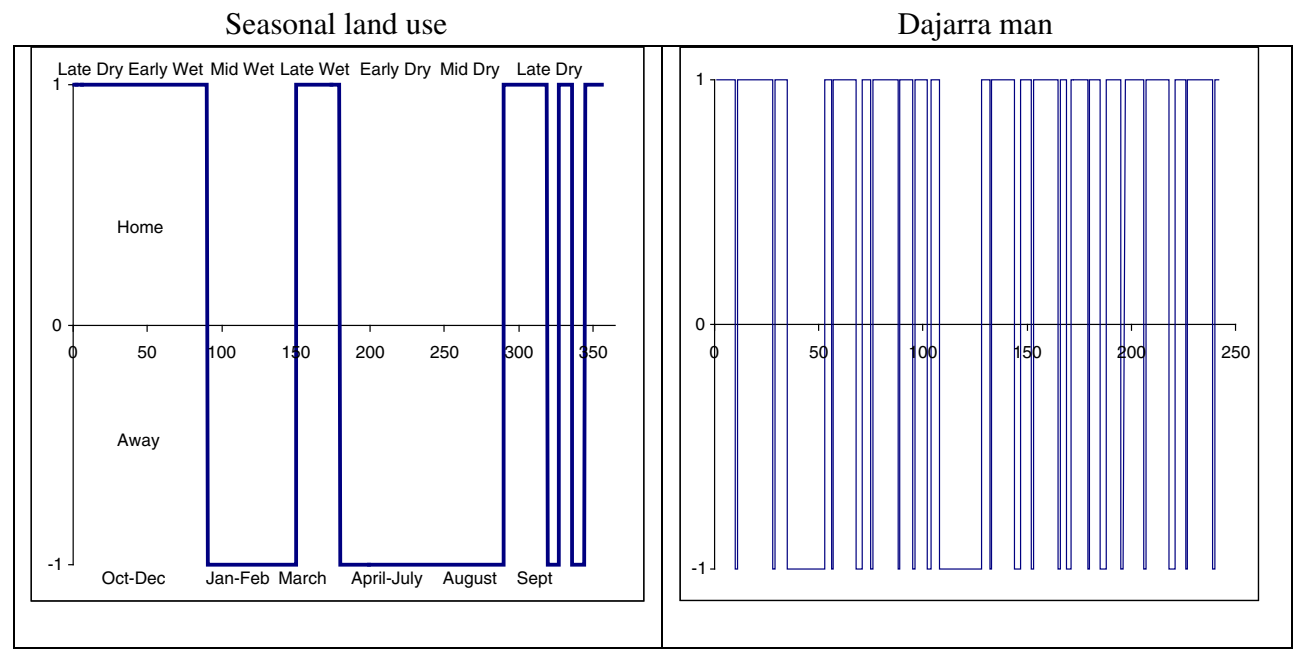

Figure 4. Illustrative space-time lifelines for selected forms of cyclic mobility.

The far more crowded mobility profile of the senior man from Dajarra is stimulated by a more varied mix of social and work-related reasons for movement. From the interviews recorded by Memmott et al. (2006), some of the factors influencing mobility are readily apparent:

'travelled to Urandangi for work on community houses and to attend land meetings. Stayed for four nights because of a funeral and rodeo. Also got a kangaroo and some wood for relatives to share it around to all the people in the camp. Go around to everyone's place and have a yarn; travelled through to Bedourie to take the kids from Dajarra for a horse and motorbike holiday programme. Camped at the rodeo grounds for three nights; going through to Amaroo for work and to look for car parts. On the way stop over take kangaroo meat to Eileen and meet up with Lake Nash people so stay a couple of nights. Spent a few days in Mt Isa for committee meetings. Stayed on for the weekend for shopping and football. Also visited kids attending Spinifex Boarding School.'

\section{SCALE AND AGGREGATION}

Hägerstrand's lifelines were originally devised for use with individual data and are remarkably effective in capturing the temporal sequences of movement from an identifiable 'home base'. They can potentially be used as a heuristic tool to help detect the underlying periodicities in travel behaviour and identify common patterns. They also serve as a valuable illustrative device, depicting regularities in transient behaviour. It is in the portrayal of aggregate data where lifelines betray their limitations: superimposing multiple lifelines on a single graph generally does little to aid clarity.

Reducing lifelines to two key indicators, frequency and duration, inevitably sacrifices substantial information but has the valuable benefit of generating measures that are infinitely scalable, from individuals to the level of multimember groups. One option is to simply calculate the means from a sample of respondents, possibly accompanied by standard deviations to reveal within-group variation. In graphical form, this would provide the basis to identify a zone on Figure 3 to describe a particular form of circulation, in place of the current nodal value.

This property of scalability is important as a bridge to measures that provide a reliable foundation for policy. But it also bears heavily on the practical issue of data collection. Biographical approaches, which encompass the detailed residential histories needed to construct lifelines, have gained increasing acceptance over the past decade (Halfacree and Boyle, 1993; McHugh et al., 1995) but the task of constructing such lifelines remains formidable. In contrast, frequency of travel and duration of trips are straightforward to collect in standard questionnaire surveys, as tourism collections have long demonstrated albeit over less extensive time frames. In a climate that seeks to minimise the cost of data collection, it would seem a sensible strategy to marry the textural richness of 
biographic data on individual life courses, with the reliability of summary indicators from representative surveys, with periodicity as the common metric.

\section{APPLICATIONS TO MAINSTREAM MOBILITY}

For indigenous Australians, we have portrayed circulation as a spatial strategy for meeting traditional obligations to kin and country and diverse objectives across multiple life domains, both social and economic. Similar imperatives have also long been recognised among peoples in a range of developing country settings (Bedford, 1973; Hugo, 1982; Chapman and Prothero, 1983), but, as anticipated by Zelinsky (1971), non-permanent forms of mobility are also gaining prominence in the developed world. Bogue et al. (2009: 4) document the steady fall of internal migration rates in the US since the mid-1960s (a decline of 35\% from 1960 to 2005), and similar trends, though less pronounced, are apparent widely across the world (Bell and Muhidin, 2009). In contrast, there is compelling evidence that temporary forms of movement are continuing to diversify and rise in intensity (McHugh et al., 1995; Green et al., 1999; Bell, 2001). The need for new analytical tools to capture and investigate circular forms of mobility is therefore not confined simply to the indigenous population in some remote corner of the Antipodes but extends much more broadly across the human population.

Such movements take a wide variety of forms ranging from everyday mobility at one end of the spectrum to the chronic relocations of transnational professionals at the other. In the spatial and temporal interstices between these extremes lies a panoply of non-permanent moves of variable spatial extent and duration. These encompass both production-related and consumption-related moves: those triggered primarily by employment, or work-related motives and those made for the purposes of pleasure (Bell and Ward, 2000). Among the former are various forms of longdistance commuting, business travel, and seasonal work (e.g. Houghton, 1993; Green et al., 1999; Hansen and Bell, 2007), whereas the latter include seasonal moves by sunbirds; weekend relocation of dual home owners; extended recreational travel by groups such as grey nomads, delegates on the conference, and convention circuit; and the oscillatory movements of children in bipolar families (e.g.
Zelinsky, 1994; Mings, 1997). Although all these types of move occupy the same broad region on a space-time chart, they are characterised by radically different periodicities, which simple summary statistics would help to tease out.

\section{CONCLUSION}

Most quantitative work that attempts to measure mobility has been framed around permanent migration whereas circulation has been treated more qualitatively. This different treatment reflects three considerations. First, data on circulation have generally been drawn from relatively small samples focused on individual life histories whereas migration data have typically been captured in Censuses or large surveys and made available at aggregate level. Second, migration has conventionally been measured as a single event or as a transition over a fixed interval, and it is much easier to handle statistically. Third, migration has been a long-standing pre-occupation of population geographers given its primacy in driving settlement change, whereas temporary movements have been regarded as ephemeral and therefore of less practical significance. The growing incidence of temporary moves and rising recognition of their significance now points to the need for a reappraisal.

In response to this need we have attempted to advance the state of the art by setting out and applying measures that capture at least one dimension of circulatory moves - their periodicity as reflected in duration and frequency. Coupling these two measures reveals unique spectral signatures that occupy distinctive positions when plotted in graphical form. By separately plotting individual lifelines we have shown that it is possible to trace the timing and reveal the complexity of motives that underpin circular mobility. But a key strength of the periodicity measure is its capacity for ready aggregation from individual to group data.

There are other aspects of the temporal domain that also invite statistical development, one of which is seasonality. It is paradoxical that while most social science devotes considerable effort to eliminating the effects of seasonal variation this remains an integral dimension of temporary mobility that has profound effects for many destination regions. Measures that capture the extent and timing of seasonality have direct 
practical application in estimating how populations of visitors and temporary residents fluctuate over the course of a year (Charles-Edwards et al., 2008). Recent work has made valuable progress in assessing suitable measures (Lundtorp, 2001; Koenig and Bischoff, 2003), but the real challenge lies in harnessing such indicators to derive reliable estimates of population flux for individual localities and regions. One logical consequence of spiralling growth in non-permanent forms of mobility is the need to reverse the contemporary impetus towards single estimates of population, based around concepts of de jure, or resident, population (United Nations, 2008) in favour of multiple measures that capture its temporal variability. Population numbers drive key decisions including fiscal allocations, service provision, and political representation, so it is imperative that they reflect the realities of a hypermobile world.

Capturing the spatial dimension of temporary moves presents another significant challenge. One approach, as pursued by Memmott et al. (2006) for indigenous Australians, is to use the pattern of journeyings to demarcate a migration or mobility region in a fashion similar to that first advocated by Young (1990). Another is to examine particular aspects of the spatial matrix. Some journeys presented here are relatively simple trips to a single destination; others involve multiple stops on a complex spatial circuit. There are techniques here to be borrowed from tourism and transport geographers on the classification of travel distance, frequency distributions of visits per trip, and archetype spatial patterns, which might also be applied to understanding circulation (Hensher, 1976; Lue et al., 1993).

The methodological challenge of defining concise and unambiguous measures that capture the complexity of circulation is clearly a daunting one. Whereas data on 'permanent' migration are relatively simple to collect and analyse, circulation involves complex and highly variable space-time sequences that lend themselves readily to tightly woven case study approaches but have proven difficult to systematise. The measures explored in this paper present some first tentative steps towards filling this void in a way that bridges the gap between individual and aggregate modes of analysis: they provide a bridge between ethnographic and quantitative traditions of inquiry. We have confined attention to elaborating one facet of the temporal dimension of circulation - its periodicity. The measures proposed are scalable, straightforward to collect, and should not be beyond the capacity of conventional census, sample survey, and case study approaches. By establishing some of the metrics that might be used to capture circulation we have made a start towards the definition of minimum data requirements. Beyond the testing of these proposals in alternative spatial and social settings, what is further needed is the elaboration of similar measures that capture other dimensions of circular mobility, particularly its seasonal profile and spatial imprint. For Australia's indigenous people, and ultimately for other populations elsewhere, the imperative is for much broader recognition of mobilities that are currently all but invisible to official population statistics. Moving beyond the now familiar call for wider adoption of biographic and ethnographic techniques (Halfacree and Boyle, 1993; Skeldon, 1995), the most pressing need is not only simply for recognition of entirely different modes of mobility behaviour but also for the tools to measure them.

\section{REFERENCES}

Altman JC. 1987. Hunter-Gatherers Today: An Aboriginal Economy in North Australia. Australian Institute of Aboriginal Studies: Canberra.

Alverson HS. 1967. Time series analysis of migratory stabilization. African Studies 26: 139-144.

Australian Bureau of Statistics. 1996. When ERPs Aren't Enough - A Discussion of Issues Associated with Service Population Estimation, Catalogue no 3112.0, ABS: Canberra.

Australian Bureau of Statistics. 1999. An Investigation to Assess the Feasibility of Producing Service Population Estimates for Selected LGAs, Catalogue no 3117.0. ABS: Canberra.

Bedford RD. 1973. A transition in circular mobility: population movement in the New Hebrides 1800-1970. In The Pacific in Transition: Geographical Perspectives on Adaptation and Change, Brookfield $\mathrm{H}$ (ed.). Edward Arnold: London; 187-229.

Bell M. 2001. Understanding circulation in Australia. Journal of Population Research 18(1): 1-18.

Bell M. 2004. Measuring temporary mobility: dimensions and issues. Paper presented at the CAUTHE Conference Session on Tourism and Temporary Mobilities, Brisbane, 10-13 ${ }^{\text {th }}$ February, 2004.

Bell M, Blake M, Boyle P, Duke-Williams O, Rees P, Stilwell J, Hugo G. 2002. Cross-national comparison 
of internal migration: issues and measures. Journal of the Royal Statistical Society A 165(3): 435-464.

Bell M, Brown D. 2006. Who are the visitors? Characteristics of temporary movers in Australia. Population, Space and Place 12(2): 77-92.

Bell M, Muhidin S. 2009. Cross-National Comparisons of Internal Migration, Human Development Research Paper 2009/30, United Nations Development Programme: New York.

Bell M, Ward G. 1998. Patterns of temporary mobility in Australia: evidence from the 1991 Census. Australian Geographical Studies 36(1): 58-81.

Bell M, Ward GJ. 2000. Comparing permanent migration with temporary mobility. Tourism Geographies 2(1): 97-107.

Bogue DJ, Ligel G, Kozloski M. 2009. Immigration, Internal Migration and Local Mobility in the US. Edward Elgar: Cheltenham.

Chapman M. 1975. Mobility in a non-literate society: method and analysis for two Guadalcanal communities. In People on the Move: Studies on Internal Migration, Kosinski LA, Prothero RM (eds). Methuen \& Co Ltd: London; 129-149.

Chapman M, Prothero RM. 1983. Themes on circulation in the third world. International Migration Review 17: 597-632.

Charles-Edwards E, Bell M, Brown D. 2008. Where people move and when: temporary population mobility in Australia. People and Place 16(1): 21-30.

Coulehan K. 1995. Keeping company in sickness and in health: Yolgnu from northeast Arnhem Land and medical related transience and migration to Darwin. In Aboriginal Health: Social and Cultural Transitions, Robinson G (ed.). NTU Press: Darwin.

Creswell T. 2006. On the Move: Mobility in the Modern World. Routledge: London.

Danaher G, Moriarty B, Danaher PA. 2006. Challenging heterotopic space: a study of the Queensland school for travelling show children. Studies in Learning, Evaluation, Innovation and Development 3(1): 40-51.

Gould WTS, Prothero RM. 1975. Space and time in African population mobility. In People on the Move: Studies on Internal Migration, Kosinski LA, Prothero RM (eds). Methuen \& Co Ltd: London; 39-51.

Green AE, Hogarth T, Shackleton RE. 1999. Longer distance commuting as a substitute for migration in Britain: a review of trends, issues and implications. International Journal of Population Geography 5(1): 49-67.

Hägerstrand T. 1963. Geographic measures of migration: Swedish data. In Human Displacements: Measurement, Methodological Aspects, Sutter J (ed.). Centre International D'Etude des Problèmes Humains: Monaco; 62-83.

Halfacree K, Boyle P. 1993. The challenge facing migration research: the case for a biographical approach. Progress in Human Geography 17(3): 333-348.
Hansen J, Bell M. 2007. Harvest trails in Australia: patterns of seasonal migration in the fruit and vegetable industry. Journal of Rural Studies 23(1): 101-117.

Hensher DA. 1976. The structure of journeys and nature of travel patterns. Environment and Planning $A$ 8: 655-672.

Houghton D. 1993. Long distance commuting; a new approach to mining in Western Australia. The Geographical Journal 159(3): 281-290.

Hugo GJ. 1982. Circular migration in Indonesia. Рориlation and Development Review 8: 59-83.

Hunter BH. 2004. Indigenous Australians in the Contemporary Labour Market 2001, catalogue no. 2052.0. Australian Bureau of Statistics: Canberra.

Koenig N, Bischoff EE. 2003. Seasonality of tourism in Wales: a comparative analysis. Tourism Economics 9(3): 229-254.

Larsen J, Urry J, Axhausen K. 2006. Mobilities, Networks, Geographies. Ashgate: Aldershot.

Lawson VA. 2000. Arguments within geographies of movement: the theoretical potential of migrants' stories. Progress in Human Geography 24(2): 173-189.

Longino CF, Marshall VW. 1990. North American research on seasonal migration. Ageing and Society 10: 229-235.

Lue CC, Crompton JL, Fesenmaier DR. 1993. Conceptualisation of multi-destination pleasure trips. Annals of Tourism Research 20: 289-301.

Lundtorp S. 2001. Measuring tourism seasonality. In Seasonality in Tourism, Baum T, Lundtorp S (eds). Pergamon: Oxford; 23-50.

McHugh KE. 2000. Inside, outside, upside down, backward, forward, round and round: a case for ethnographic studies in migration. Progress in Human Geography 24(1): 71-89.

McHugh KE, Hogan TD, Happel SK. 1995. Multiple residence and cyclical migration: a life course perspective. The Professional Geographer 47(3): 251-267.

Memmott P, Long S, Thomson L. 2006. Indigenous Mobility in Rural and Remote Australia. Australian Housing and Urban Research Institute: Melbourne.

Mings RC. 1997. Tracking snowbirds in Australia: winter sun seekers in far North Queensland. Australian Geographical Studies 35(2): 168-182.

Mitchell JC. 1956. Urbanisation, detribalization and stabilization in Southern Africa: a problem of definition and measurement. In Social Implications of Industrialization and Urbanization in Africa South of the Sahara. UNESCO: Paris; 693-711.

Morphy F. 2007. Uncontained subjects: 'population' and 'household' in remote Aboriginal Australia. Journal of Population Research 24(2): 163-185.

Peterson N. 2004. Myth of the "walkabout": movement in the Aboriginal domain. In Population Mobility and 
Indigenous Peoples in Australasia and North America, Taylor J, Bell M (eds). Routledge: London and New York; 223-239.

Prout S. 2009a. Vacuums and veils: engaging with statistically invisible indigenous population dynamics. Geographical Research 47(4): 408-421.

Prout S 2009b. Security and belonging: reconceptualising Aboriginal mobilities in Yamatji country, Western Australia. Mobilities 4(2): 177-202.

Rees P, Bell M Duke-Williams O, Blake M. 2000. Problems and solutions in the measurement of migration intensities: Australia and Britain compared. Population Studies 54(2): 207-222.

Roseman CC. 1971. Migration as a spatial and temporal process. Annals of the Association of American Geographers 61: 589-598.

Schwanen T, Kwan MP 2009. Doing critical geographies with numbers. The Professional Geographer 61 (4):459-464.

Sheller M, Urry J. 2006. The new mobilities paradigm. Environment and Planning A 38(2): 207-226.

Silm S, Ahas R. 2010. The seasonal variability of population in Estonian municipalities. Environment and Planning A 42(10): 2527-2546.

Skeldon R. 1995. The challenge facing migration research: the case for greater awareness. Progress in Human Geography 19: 91-96.

Smith SK. 1989. Toward a methodology for estimating temporary residents. Journal of the American Statistical Association 84(406): 430-436.

Smith SK. 1994. Estimating temporary populations. Applied Demography 9(1): 4-7.

Smith BR. 2000. Between Places: Aboriginal Decentralisation, Mobility and Territoriality in the Region of Coen, Cape York Peninsula (Australia). Unpublished PhD thesis, Department of Anthropology, London School of Economics and Political Science.

Smith SK. 2007. Temporary migration: a case study of Florida. Population Research and Policy Review 26: 437-454.
Standing G. 1982. Conceptualising Territorial Mobility in Low Income Countries. International Labour Office: Geneva.

Stillwell J, Congdon P (eds). 1991. Migration Models. Belhaven Press: London.

Taylor J. 1986. Measuring circulation in Botswana. Area 19(3): 203-208.

Taylor J, Bell M. 2004. Continuity and change in Indigenous Australian population mobility. In Population Mobility and Indigenous Peoples in Australasia and North America, Taylor J, Bell M (eds). Routledge: London and New York; 13-44.

United Nations. 2008. Principles and Recommendations for Population and Housing Censuses, Revision 2, Statistical papers Series M No. 67/Rev.2 ST/ESA/STAT/ SER.M/67/Rev.2. Department of Economic and Social Affairs: New York.

Uzzell D. 1976. Ethnography of migration: breaking out of the bi-polar myth. In New Approaches to the Study of Migration, Guillet D, Uzzell D (eds). Rice University Studies: Houston; 45-54.

Young EA. 1979. Residence history analysis: Papua New Guinea. In Residence History Analysis, Pryor RJ (ed.). Studies in Migration and Urbanisation No. 3, Department of Demography, The Australian National University, Canberra: Canberra; 39-51.

Young EA. 1990. Aboriginal population mobility and service provisions: a framework for analysis. In Hunter-Gatherer Demography: Past and Present, Meehan B, White N (eds). Oceania Monograph 39, University of Sydney: Sydney; 186-196.

Young EA, Doohan K. 1989. Mobility for Survival: A Process Analysis of Aboriginal Population Movement in Central Australia. North Australia Research Unit, The Australian National University: Darwin.

Zelinsky W. 1971. The hypothesis of the mobility transition. Geographical Review 61: 219-249.

Zelinsky W. 1994. Conventionland USA: the geography of a latterday phenomenon. Annals of the Association of American Geographers 84(1): 68-86. 